\title{
Yucatan Pig
}

National Cancer Institute

\section{Source}

National Cancer Institute. Yucatan Pig. NCI Thesaurus. Code C77108.

Originating from Mexico and Central America, this breed has a straight back and no potbelly, short snout, sparse hair coat and medium size ears. The Yucatan pig is slate gray to black in color. Its uses in biomedical research are varied and include diabetes research, cardiovascular research, angiogenesis, and ophthalmological research among others. 